\title{
Adolescent Friendship Networks and Trajectories of Binge Drinking
}

Michael Pollard, Harold D. Green, David P. Kennedy, Myong-Hyun Go, and Joan S. Tucker

RAND Labor \& Population

WR-998

May 2013

This paper series made possible by the NIA funded RAND Center for the Study of Aging (P3OAG012815) and the NICHD funded RAND Population Research Center (R24HD050906).

RAND working papers are intended to share researchers' latest findings and to solicit informal peer review. They have been approved for circulation by RAND Labor and Population but have not been formally edited or peer reviewed. Unless otherwise indicated, working papers can be quoted and cited without permission of the author, provided the source is clearly referred to as a working paper. RAND's publications do not necessarily reflect the opinions of its research clients and sponsors. RAND $尺$ is a registered trademark. 


\title{
Adolescent Friendship Networks and Trajectories of Binge Drinking
}

\author{
Michael S. Pollard \\ Harold D. Green \\ David Kennedy \\ Myong-Hyun Go* \\ Joan S. Tucker \\ (RAND, Santa Monica, CA) \\ (*The Asan Institute for Policy Studies)
}

Corresponding Author: Michael S. Pollard, RAND Corporation, 1776 Main Street, Santa Monica, CA 90407-2138. Phone 310-393-0411 x7627; Fax 310-260-8160;

E-mail: mpollard@rand.org

Work on this project was supported by grant 1R21AA017946 from the National Institute on Alcohol Abuse and Alcoholism (PI: Michael Pollard).

Acknowledgements: This research uses data from Add Health, a program project designed by J. Richard Udry, Peter S. Bearman, and Kathleen Mullan Harris, and funded by a grant P01-HD31921 from the National Institute of Child Health and Human Development, with Cooperative funding from 17 other agencies. Special acknowledgment is due Ronald R. Rindfuss and Barbara Entwisle for assistance in the original design. Persons interested in obtaining data files from Add Health should contact Add Health, Carolina Population Center, 123 W. Franklin Street, Chapel Hill, NC 27516-2524 (addhealth@unc.edu) 


\section{Adolescent Friendship Networks and Trajectories of Binge Drinking Abstract}

We examine how adolescent friendship networks are linked to binge drinking trajectories into young adulthood using Add Health. We add to the literature by examining whether an individual's structural position (group member, liaison or isolate) in friendship networks is linked to longitudinal alcohol use, above and beyond number of drinking friends. Trajectories of "binge drinking episodes per month" are first modeled using semi-parametric longitudinal mixture models. Individuals are assigned to trajectory groups based on posterior probabilities of membership. Friendship network structural characteristics are modeled using NEGOPY. Multinomial logit models of trajectory group membership are then estimated, and include information on network position, number of drinking friends, as well as a range of controls. We identify five trajectories of binge drinking. Structural position is associated with use trajectories: bingeing group membership and liaison to bingeing groups predicts higher trajectories. Network effects are strongly associated with bingeing in school, but not after. 


\section{Adolescent Friendship Networks and Trajectories of Binge Drinking}

This study examines how friendship networks in adolescence are linked to alcohol use trajectories into young adulthood, using the National Longitudinal Study of Adolescent Health (Add Health) Waves 1-3 and the friendship network data from the saturated school sample (all students in the saturated schools were interviewed). We test whether number of self-reported drinking friends are linked to longitudinal alcohol use (bingeing). We add to the literature by further examining whether an individual's structural position (group member, liaison or isolate) in friendship networks is linked to longitudinal bingeing.

This study addresses three primary questions:

1) Can we identify developmental patterns of binge drinking in adolescence into young adulthood?

2) Are these developmental patterns linked to reports of perceived drinking friends in adolescence?

3) Do friendship network position measures add explanatory power (i.e., the way individuals are tied to other individuals, not simply self-reports of friends' behaviors and the number of drinking friends)?

\subsection{Alcohol use continues to be a significant long-term health threat affecting many adolescents and young adults in the United States.}

National data from Monitoring the Future indicate that alcohol is the most widely used substance by teenagers today. Current estimates suggest that $41 \%$ of adolescents have consumed alcohol by $8^{\text {th }}$ grade and nearly $75 \%$ have tried by $12^{\text {th }}$ grade (Johnston et al. 2007). Over half $(56 \%)$ of $12^{\text {th }}$ graders, and $20 \%$ of $8^{\text {th }}$ graders report being drunk at least once. A more serious health concern than general use is binge drinking. Rates of binge drinking leveled off 7-10 years ago, and in 2002 a drop in drinking and drunkenness began to appear at all grade levels. By 2006 this decline had stalled for $8^{\text {th }}$ graders, reversed for $10^{\text {th }}$ graders, and continued only for $12^{\text {th }}$ graders. Adolescent alcohol misuse is a major public health concern, with consequences including driving intoxicated, suicidal orientations, alcohol dependence, early sexual activity, and dropping out of school (Brown and Lourie 2001; Gomberg 1997; Nelson, Heath and Kessler 1998; Prendergast 1994; Turrisi and Jaccard 1992; Windle, Miller-Tutzauer and Domenico 1992). Adolescence is also a critical stage of physiological development - rapidly changing body systems may be especially vulnerable to alcohol's effects, and brain and hormonal maturation may be affected in the long term (Spear 2000). Thus, the critical periods for successful alcohol prevention and intervention are during adolescence and the transition to young adulthood, the developmental periods which are the focus of this project. Although considerable progress has been made in identifying risk and protective factors associated with youth drinking (Donovan 2004; Gil, Vega and Turner 2005; Maney, Higham-Gardill and Mahoney 2002; McCarty et al. 2004; Power et al. 2005), psychosocial prevention programs tend to have small to medium effects on youth 
drinking behavior (National Institute on Alcohol Abuse and Alcoholism 2004/2005) and thus may be further enhanced by gaining a clearer understanding of the natural course of drinking and its determinants.

\subsection{Peer relationships are associated with youth drinking behavior, but the nature of these associations is far from understood.}

Youth substance use is undoubtedly influenced by a complex array of interrelated risk factors. In the case of drinking researchers have focused on such diverse factors as social influences, school and community contexts, intrapersonal characteristics (e.g., mental health), and delinquency (Donovan 2004; Hawkins, Catalano and Miller 1992; Maney, Higham-Gardill and Mahoney 2002; Nash and McQueen 2005; Petraitis, Flay and Miller 1995). Among these factors, one type has received disproportionate attention: friendship and other peer relationships. Numerous cross-sectional and prospective studies have found that exposure to pro-drinking peer behaviors and attitudes is associated with the initiation and escalation of alcohol use during adolescence and emerging adulthood (Bahr, Hoffman and Yang 2005; Bauman and Ennett 1996; Curran, Stice and Chassin 1997; Ennett et al. 2006; Mason and Windle 2001; Prinstein, Boergers and Spirito 2001). However, despite the considerable number of studies on peer relationships and drinking, this literature has only scratched the surface in terms of understanding the factors contributing to peer similarities in drinking, the diversity of peer influences relevant to drinking, and the conditions under which youth are susceptible versus resilient to drinking-related peer influences.

We note that there is no single theory of how social network processes influence behavior. Rather, numerous sociological and social psychological theories, such as social learning theory (Akers, 1985), have been developed to explain the interpersonal processes through which social networks influence health behavior. In line with these various approaches, we view peer networks as influencing individual behavior through multiple mechanisms, the primary ones being to: (a) shape the individual's social environment and exposure to risks; (b) influence the availability of information and tangible and emotional supports; and (c) affect the individual's beliefs and attitudes through social norms and monitoring mechanisms.

Relatively few studies have used social network analysis to understand peer influences on youth drinking behavior. Some of this research on peer networks and drinking has focused on the network composition of adolescent drinkers and nondrinkers, finding that at both the best friend (dyad) and entire group levels, individuals report similar behaving similarly; either all predominantly drinking or all non-drinking (Kobus 2003; Paschall, Bersamin and Flewelling 2005; Windle 2003). Other research, focusing instead on smoking, has examined whether adolescents who fill various social positions that characterize peer group structure [e.g., part of a peer group (clique), clique liaison, isolate] differ in their drinking behavior. Such research suggests that peers who are both least embedded in peer networks and most embedded are more likely to be smokers (Ennett and Bauman 1993), as are those with higher social status and closer social proximity to peer substance users (Ennett et al. 2006). 


\subsection{Peer networks}

There is a large body of literature that supports the assumption that peer groups play a critical role in the initiation and maintenance of substance use behaviors during adolescence. However, Ennett and Bauman (1993) were the first to demonstrate that the structure of the peer group is also linked to substance use - specifically smoking behaviors. Peer group structure refers to the way in which the relational ties between individuals are organized in the network, and describes an individual's location in those ties. The three primary social network positions that adolescents may inhabit include group members, isolates, and liaisons. A group member is a participant in a tightly knit group of interacting peers. An isolate is a participant with no or relatively few links to peers. A liaison is a member of a social system who links two or more groups together, without being a member in any of the groups.

Network position is relevant to drinking behavior, as different positions are associated with different levels of interaction with peers. Social network analysis allows direct identification of the structural properties of peer relationships and the substance use of peers, which are both key to understanding peer context (Valente, 2003). For example, group members may be more susceptible to peer influence because they have greater and more intense exposure to peers and their behaviors. Consistent with these assumptions, Ennett and Bauman (1993) identified associations between network position, peer smoking behavior, and personal smoking behavior using cross-sectional data. Although they hypothesized that isolates would have the lowest levels of smoking in light of their low number of network ties, this initial study found that isolates had substantially higher levels of smoking than group members or liaisons (who were comparable). However, in later work this finding was refined to identify isolates as significantly more likely to smoke than others at age 13, but not at younger or older ages (Ennett et al., 2006). Further, and fully consistent with the assumptions, individuals who were at closer proximity to substance users were more likely to use substances, and individuals in high smoking prevalence networks were more likely to smoke.

We are aware of no studies that examine alcohol use and friendship networks, although a handful of additional studies consider network structure position and smoking behaviors. Fang, Li, Stanton and Dong (2003) used data on roughly $1,0006^{\text {th }}, 8^{\text {th }}$, and $10^{\text {th }}$ grade students in Beijing, China to explore the relationship between peer social network position (group members, liaisons, and isolates) and smoking experimentation. Turner, West, Gordon, Young and Sweeting (2006) examined roughly 400 students ages 13 and 15 at two large urban school in Scotland, identifying "group members," "isolates," "dyads," and "peripheral" structures. The peripheral structure was similar to "liaison" although the peripheral individual may only link to one group. The "dyad" structure identified an isolated friendship pair (considered isolates in the present study). Pollard et al. (2010) used roughly 800 students from the Add Health data to examine friendship network position (group members, liaisons, and isolates) and trajectories of cigarette use over six years. Henry and Kobus (2007) used network data from $1,1006^{\text {th }}$ grade students in and around Chicago to identify individuals as group members, isolates, or liaisons.

The Chinese and Scottish data generally support Ennett and Bauman's (1993) initial study results, as isolates and isolate-like dyads were more likely than group members or liaisons to have experimented with smoking (China), to be currently smoking (Scotland), or to hold more negative attitudes towards smoking (Scotland) compared to 
other network structure types. However, the Chinese data also noted that the opposite was true among $10^{\text {th }}$ grade boys, who were less likely to have smoked if they were isolates compared to group members or liaisons. The Add Health data did not support Ennett and Bauman's (1993) findings, as members of smoking groups and liaisons to smoking groups were most likely to belong to higher use smoking trajectories. The Chicago data also did not support the original Ennett and Bauman (1993) findings; results indicated that liaisons were more likely to smoke than group members or isolates.

Thus, while several studies have identified peer substance use as a predictor of personal substance use trajectory membership, none of these studies have examined alcohol use or binge drinking.

\subsection{The present study}

We build on prior work by employing a large, ethnically diverse nationally representative longitudinal sample of adolescents that contains detailed personal alcohol consumption information (quantity-frequency interaction, or QFI), both perceptions of friends' drinking as well as measures of actual peer binge drinking behavior, and complete social network information. Thus, our study addresses three primary aims. First, we identify developmental trajectories of binge drinking in a nationally representative cohort of youth who were initially recruited in grades 9-11 and interviewed three times over a six-year period. Second, we investigate how perceptions of best friend drinking at baseline predicts the adolescent's developmental trajectory of binge drinking over a six-year period. Third, we examine whether the adolescent's network structural position (i.e., group member, liaison, or isolate) in relation to the actual drinking behavior of peers predicts trajectory group membership, above and beyond perceptions of the number of best friends who drink.

Based on prior findings that closer proximity to smoking peers is associated with personal smoking behavior, we anticipate that an individual's position in a social network will similarly predict developmental binge drinking patterns as a reflection of the longerterm impact of proximity to drinking peers. Specifically, members of non-bingeing groups will be least likely to binge in the future, or will binge at lower frequencies. Members of bingeing groups, conversely, will be most likely to binge and continue to binge at high frequencies. Liaisons attached to a bingeing group will be more likely to binge and binge more frequently than liaisons who are only attached to non-bingeing groups. It is unclear how isolate status is associated with binge drinking trajectory, as prior research on the substance use of isolates is mixed. While the question of peer influence versus peer selection remains outstanding, the bulk of the literature cited above generally assumes influence over selection. However, identifying associations between network structure and long-term drinking behaviors, regardless of causal ordering, stands to enrich our understanding of adolescent drinking behaviors.

\section{Method}

\subsection{Data}

This analysis is based on data drawn from Waves I through III of the National Longitudinal Study of Adolescent Health (Add Health). Add Health is a nationally representative study of adolescents in grades 7 through 12 in the United States in 1995 
who have been followed with multiple interview waves into young adulthood. The sampling frame included all high schools in the United States. Add Health is the largest study of adolescent friendship networks ever conducted, as well as the only such study with a nationally representative sample. Over 90,000 participants from 145 schools were asked to report on their own drinking behavior (as well as other behaviors and attitudes) and to identify up to 10 of their friends. Each of these friends, in turn, reported on their own drinking behavior and independently identified up to ten of their own friends (five male and five female). Of the initial 90,000 respondents, a baseline sample of 20,745 adolescents aged 12-19 was interviewed at home between April and December 1995 (Wave I), between April and August 1996 (Wave II), and again between August 2001 and April 2002 (Wave III). Over 15,000 Add Health respondents were re-interviewed at Wave III. The overall sample is representative of United States schools with respect to region of the country, urbanicity, school type (e.g., public, parochial, private nonreligious, military), ethnicity, and school size. See Harris et al. (2008) for more details on the Add Health design and longitudinal data. A key strength of this dataset is that in 16 so-called "saturated" schools, all students in the schools completed a similar friendship nomination process in each of the two follow-up, in-home interviews. This allows for a rigorous identification of friendship networks, as well as provides reports of personal drinking behavior from each respondent, rather than relying solely on an individual's perception of his or her friends' drinking.

In all, Wave I participants who completed the in-home survey included $79 \%$ of all sampled students $(\mathrm{N}=20,745)$ and $98 \%$ of the saturation school sample $(\mathrm{N}=3,702)$. Wave II participants included the participants from Wave I who still met the grade eligibility requirements (maximum of $12^{\text {th }}$ grade). $88 \%$ of adolescents who completed a Wave I inhome survey $(\mathrm{N}=14,738)$, and $75 \%$ of adolescents from the Wave I saturation sample $(\mathrm{N}=2,776)$, were re-interviewed at Wave II. The respondents interviewed at Wave III (by now age 18-26) represent $76 \%$ of adolescents who completed a Wave I in-home survey $(\mathrm{N}=19,962)$ and $80 \%$ of adolescents from the Wave I saturation sample $(\mathrm{N}=2,959)$.

\subsection{Samples}

The overall analysis proceeds in two stages: first we identify binge drinking trajectories, next we link those trajectories to friendship network information. For all analyses we follow the sample of students who were in grades 9 through 11 at Wave I across all three Waves ${ }^{1}$. In the first stage of the analysis (identification of binge drinking trajectories), we rely on respondents in grades 9 - 11 from all of the schools who had valid drinking information at all three waves $(\mathrm{N}=6,832)$ in order to maximize the information available. At Wave I, these individuals range in age from 14-18 (94\% were ages 15-17). In the second stage of the analysis, we restrict the sample to the subset of $9^{\text {th }}$ through $11^{\text {th }}$ graders from so-called "saturated" schools with complete information on the

\footnotetext{
${ }^{1}$ Respondents in grade 12 at baseline were not interviewed at Wave II, and thus we have excluded them from the analysis. Preliminary analyses conducted separately for each grade indicated that the binge drinking trajectories of grades 9 - 11 were comparable, while grades 7 and 8 were not; thus the lower grades are also excluded here. In order to maximize model power, grades 9-11 were ultimately combined, rather than examined individually, in light of their similarity in trajectory patterns.
} 
relevant variables $(\mathrm{N}=1,648)$. In the saturated schools, substantial effort was made to track down and interview every student.

\subsection{Key measures}

\subsubsection{Binge Drinking trajectory group membership}

The final outcome measure in our analysis is the estimated binge drinking trajectory to which an individual belongs. The bingeing trajectories are derived as described in the analytic strategy section, based on the average number of binge episodes per month at each of the three Waves. Respondents were asked "Over the past twelve months, on how many days did you drink five or more drinks in a row." If the respondent indicated that he or she had not binged in the past year, the average binge episodes variable had a value of 0 . Table 1 presents summary statistics for the dependent and independent variables used in the analyses. The average binge episodes per month increased steadily across the Waves, from 1.0 at Wave I to 1.8 at Wave III.

\section{[Table 1 About Here]}

\subsubsection{Network position}

The primary independent variable of interest in the analysis is the individual's network position at Wave I: member in a binge drinking group, member in a nonbingeing group, liaison only to a bingeing groups, liaison only to non-bingeing groups, liaison to both bingeing and non-bingeing groups, or isolate ${ }^{2}$. The network classifications of isolate, liaison, and group member at Wave I are derived using the social network program NEGOPY as detailed in the analytic strategy section (Richards, 1995). Figure 1 presents a visual example of what each of these structural positions looks like.

A group member is generally defined as a participant in a tightly knit group of interacting peers. For these analyses, adolescents were classified as a group member if they had $50 \%$ or more of their ties directed to members of the same group. Following Ennett and Bauman (1993) and Pollard et al. (2010), group members are further identified as belonging to a "bingeing group" if any of the other group members are binge drinkers (regardless of the focal individual's drinking status). A liaison is a member of a social system who serves a linking function between its parts owing to the fact that the actor maintains many relations outside of particular groups. For these analyses, adolescents were classified as liaisons if they connected one or more groups with other groups or nodes. An isolate is a participant with no or relatively few links. For these analyses, adolescents were classified as isolates if they had at most one tie with the rest of the network. The process of identifying network position is described in Section 2.4.2.

\section{[Figure 1 About Here]}

\footnotetext{
${ }^{2}$ The Add Health data includes a variety of pre-constructed basic network descriptor variables (such as nominations sent [out-degree] and received [in-degree], centrality) as well as ego-centered network measures pertaining to grade, race, and age heterogeneity, and some network mean behaviors. However, the pre-constructed data do not include information on the network structures, or the behaviors of those structures, that we consider here.
} 


\subsubsection{Control variables}

Basic demographic control variables are included in the analyses. Demographic measures include gender, age, and race/ethnicity, coded as one of four groups: nonHispanic white, non-Hispanic black, Hispanic, and other ${ }^{3}$.

Perceived peer drinking is assessed using the respondent's report of how many of their three best drink alcohol at least once monthly (at Wave I).

\subsection{Analytic strategy}

\subsubsection{Identifying drinking trajectory groups}

We use PROC TRAJ in SAS 9.1.3 to perform latent class growth analysis (Nagin, 1999) and identify the discrete developmental trajectories of binge drinking using the average number of binge episodes per month over the past year. Unlike the popular latent growth curve analysis techniques that combine structural equation modeling and hierarchical linear modeling (Duncan, Duncan, Strycker, Li \& Alpert, 1999; Raudenbush \& Bryk, 2002), in which the model structure is severely hampered with three data points, the latent class growth analysis method relies on a multinomial modeling strategy (estimating the parameters of finite mixture models by maximum likelihood), permitting cross-group differences in the level and shape of trajectories in a fashion that is much more flexible with only three data points (Jones, Nagin, \& Roeder, 2001; Nagin \& Tremblay, 2001). This procedure has previously been applied to the Add Health data to examine smoking trajectories (Pollard et al 2010), trajectories of depression (Costello, Swendsen, Rose, \& Dierker, 2008) and delinquency trajectories (Aalsma \& Tong, 2008). We incorporate sample weights in all analyses. See Jones, Nagin and Roeder (2001) for a detailed discussion of the likelihood function and estimation of these models.

Trajectories are calculated based on grades 9-11 in the entire Add Health sample (not just the saturated school network sample). Sampling weights reflecting eligible Wave I respondents interviewed at both Wave II and Wave III are used in the estimation of trajectory groups. For later regression analyses, these are the trajectories into which respondents are assigned. It should be noted as a consistency check that we are able to replicate the same model in the reduced network sample.

There is no definitive statistic for determining the optimal number of trajectory groups that describes the data. However, the BIC criterion is generally used when testing latent class growth models (e.g., Laub, Nagin \& Sampson, 1998). The model with the smallest absolute BIC is chosen. The BIC rewards parsimony and tends to favor fewer groups, but it is known to be consistent (Keribin, 1998). Respondents are assigned to the trajectory for which they have the largest posterior probability estimate - the group that best conforms to the individual's observed behavior (Muthén \& Shedden, 1999).

\subsubsection{Classifying individuals on network structural characteristics}

Friendship network structural characteristics at Wave I for the saturated schools are modeled using NEGOPY. NEGOPY is one of the original and most commonly used network analysis packages. It is based on Eigenvector decomposition, and detects groups via iterative averaging (comparing the percentage of ties within groups versus between groups). NEGOPY classifies nodes into three broad categories: group members, liaisons, and isolates. Group members are those with $50 \%$ or more ties are directed to members of

\footnotetext{
${ }^{3}$ Sample size limitations prevented distinct consideration of Asians.
} 
the same group. Liaisons are nodes that connect one or more groups with other groups or nodes, and isolates are those with at most one tie with the rest of the network. In addition, each node in the complete sociocentric network is assigned to a network position. This assignment is deterministic in the sense that each node is assigned to a position and this assignment is exclusive to that position.

Network ties are also weighted to incorporate information about tie strength, based primarily on reciprocated tie nominations and an additional series of questions regarding the level of dyadic activity, such as whether the focal individual visits the nominee's home or talks with the nominated over the phone. Group identification by NEGOPY is optimized when we have information on the number of connections as well as the strength of those connections (Seary, 2005). We use dyadic activity information in the In-Home interview questionnaire to estimate the level of "closeness" between two friends to capture the strength of connections. For each nominated friend, adolescents were asked whether they had engaged in the following behaviors during the past 7 days: 1) Visited the friend's home; 2) Talked with the friend over the phone; 3) Discussed a problem with the friend; 4) "Hung out" with the friend after school; and 5) Spent time with the friend during the weekend. We obtain the tie strength score by averaging the five items, and further transformed the scores by giving more weight to those who shared more dyadic activities.

\subsubsection{Predicting trajectory group membership from best friend drinking and network structural characteristics}

Once trajectory groups are identified using SAS PROC TRAJ and individuals have been assigned to the trajectories, a multinomial logit model of trajectory group membership is estimated, including information on perceived number of drinking best friends, demographic controls, and network position measures (group member, liaison, isolate. Regression analyses are corrected for complex sample design effects using strata, cluster, and weight variables (Chantala \& Tabor, 1999).

Multinomial Logit Predicting Trajectory Group:

$$
\log \left(p_{i j} / p_{i J}\right)=\beta_{j} \mathrm{x}_{i} \quad j=1, \ldots \ldots, J-1 \text { groups }
$$

where $\mathrm{X}_{i}=$ network position, perceived best friend drinking and control variables

\section{Results}

\subsection{Estimated binge drinking trajectories}

Figure 2 presents the results of the latent class growth analysis. Sequential comparisons of models with $\mathrm{k}$ and $\mathrm{k}+1$ classes indicate that a five-class model provides the best fit to the data. The five-class model also produces well-defined classes; mean group assignment probabilities for the six classes range from $82 \%$ to $99 \%$. The five binge drinking trajectory classes: Never-bingers (25.2\%), Experimenter $(25.2 \%)$, Monthly Bingers (40.4\%), School Bingers (4.8\%), and Young Adult Bingers (4.3\%).

[Figure 2 About Here] 
Monthly bingers experienced an average of roughly one binge episode per month across all three waves. School bingers experienced frequent bingeing during high school (Waves I and II), more than ten times per month on average, but declined to about the level of Monthly bingers after six years (Wave III). Young Adult bingers averaged a few binge episodes during high school, but six years later experienced very high frequency binge drinking (roughly 20 episodes per month, on average). Experimenters reported only minimal experience with binge drinking across the six-year span, while neverbingers reported no binge drinking experience during the entire period.

\subsection{Predicted trajectory group membership using best friend drinking and network structural characteristics}

Using the set of trajectories identified in section 3.1, a multinomial logistic regression is estimated and summarized in Table 2. Trajectories are estimated as a function of perceived number of best friends who drink alcohol at least monthly, demographic controls, and as a function of network position (i.e., bingeing group member, non-bingeing group member, liaison to bingeing groups only, liaison to nonbingeing groups only, liaison to bingeing and non-bingeing groups, or isolate). The "never-binged" trajectory serves as the reference category.

\section{[Table 2 About Here]}

Table 2 presents results of the multinominal logistic regression model predicting trajectory group membership. Results indicate that perceiving a greater number of drinking best friends is associated with greater odds of an adolescent being in any of the binge drinking trajectories compared to being a never-binger, particularly the school binger trajectory.

Network structure is also significantly associated with binge trajectory in the expected manner. Adolescents who are members of bingeing groups are more likely than members of non-bingeing groups to belong to relatively higher binge trajectories, particularly the monthly and school bingers. Membership in a bingeing group has these effects above and beyond the effect associated with the perceived number of best friends who drink. Further, liaisons linked to bingeing groups are more likely than members of non-bingeing groups to belong to higher binge trajectories, especially the school binge and young adult bingers. In contrast, there were no significant differences between liaisons linking non-bingeing groups and members of a non-bingeing group in their likelihood of being in a particular binge trajectory group, above and beyond the impact of perceived number of best friends who drink, nor were isolates significantly more likely to belong to any of the higher binge trajectories.

\section{Discussion}

Analyses based on this nationally representative sample indicate that among individuals originally in grades 9-11 (primarily ages 15-17), and followed over a six-year period, there are five unique developmental trajectories of binge drinking: Neverbingers, experimenters, monthly bingers, school bingers, and young adult bingers. 
Further, the number of (perceived) best friends who drink predicts membership in higher binge trajectories. These associations are robust to controls on gender, race/ethnicity, and age.

The present study also identifies that the way in which the individual is linked to these friends additionally predicts bingeing trajectory class membership over a six-year period. Adolescents who belong to a bingeing group, or are a link between bingeing groups, are at increased risk for belonging to a higher binge trajectory group compared to those who are members of a non-bingeing group. Further, they appear to be at highest risk for memberships in trajectories groups characterized by the highest levels of bingeing either initially or over time. These results also highlight the importance of distinguishing the drinking status of network structures (i.e., the bingeing status of the group to which an adolescent belongs or serves as a liaison to). This finding extends the cross-sectional associations between substance use (tobacco) and network structure identified by Ennett and Bauman (1993) and Ennett et al. (2006) by demonstrating the long-lasting impact of network position on binge drinking, as well as mirroring the results found for associations between network position and longitudinal smoking trajectories (Pollard et al. 2010). The result demonstrates a lasting association between friendship network features and longer-term heavy binge drinking behaviors, above and beyond simply the number of drinking best friends.

It should also be highlighted that isolates and liaisons to non-bingeing groups are no more at risk of higher binge trajectory membership than members of a non-bingeing group. Previous literature examining substance (tobacco) use, based on smaller samples has suggested that both isolates (Ennett \& Bauman, 1993; Fang et al., 2003; Turner et al., 2006) and liaisons (Henry \& Korbus, 2007) are at increased risk of greater tobacco consumption. Larger sample sizes, such as in this study and Ennett et al. (2006), appear to attenuate the association between isolate status and bingeing/smoking risk substantially.

The link between network position and developmental trajectory also provides further insight into identifying particularly at-risk individuals. Of note, the influence of high school friendship networks is strongly linked to high bingeing while in school, but once individuals leave school the network effects do not necessarily persist. Specifically, membership in a bingeing group or being a liaison to a bingeing group were both strongly associated with the school binger trajectory. This trajectory consists of individuals who binge heavily at Waves 1 and 2 of the data, but by Wave 3 (six years after Wave 1), these high bingers appear no different from the monthly bingers in terms of binge frequency. During Waves 1 and 2 respondents are still attending school; once the respondents have left school (and presumably the network structure they were in during school), the impact of that network's drinking behavior is attenuated for these early high bingers.

Conversely, the young adult binge trajectory consists of an equally sized group of individuals who approximate the "monthly binge" trajectory while in high school, but by wave 3 they binge at very high frequencies. Individuals who act as liaisons to drinking groups only are more likely to belong to the young adult binge trajectory, suggesting that tangential attachments to drinking groups may ultimately offer more heavy drinking opportunities in the future. Whether these individuals ultimately join these, or other, drinking groups (potentially during college) is an area in need of further exploration. 
For instance, prior studies investigating predictors of substance use trajectory have noted that individuals who "look similar" to one another initially on the risk factors considered, such as psychosocial characteristics and parental substance use, may later follow very different developmental paths. In the current study, monthly bingers and young adult bingers both begin with similar levels of binge frequency at the first and second observations, but five years later the young adult bingers have the highest average monthly binge episodes by far. The results in Table 2 suggest that individuals who act as liaisons to bingeing groups are at particular risk of membership in the young adult binge trajectory. Perhaps there is something about holding this structural position that makes individuals more prone to become heavier bingers that is not otherwise apparent.

It is important to note that the results are based on students in grades 9-11 at baseline. The trajectories of this high school group were distinct from those at the younger middle school grade levels (not shown). This suggests both that there may be some developmental turning point at this particular portion of the life course, and also that the association between network position and bingeing trajectory may vary by age. Future research that explicitly examines the moderating effect of age on the link between network position and long-term bingeing behavior would be welcome.

While this study contributes to understanding the ways in which peers are associated with individual bingeing behaviors over time, the precise mechanisms through which these effects operate are still largely unidentified. A critical piece of the puzzle remains the relative extent to which peers influence bingeing behavior, and the extent to which peers reflect the selective friendship choices of an individual based on their preexisting behaviors and attitudes. Overcoming the substantial methodological challenges of disentangling these two processes is the next substantial hurdle in peer effects research. Regardless, the present study suggests features of an individual's social network have long-lasting associations with bingeing behaviors. 


\section{REFERENCES}

Aalsma, M. \& Tong, Y. (2008). Delinquency trajectories and young adult health care access. Journal of Adolescent Health, 42, 15-15.

Akers, R. L. (1985). Deviant behavior: A social learning approach. Wadsworth Press, Belmont.

Bahr SJ, Hoffman JP, Yang X. Parental and peer influences on the risk of adolescent drug use. (2005). The Journal of Primary Prevention 26:529-551.

Bauman KE, Ennett ST. (1996). On the importance of peer influence for adolescent drug use: Commonly neglected considerations. Addiction 91:185-198.

Brown LK, Lourie KJ. (2001). Motivational interviewing and the prevention of HIV among adolescents. In: Monti PM, Colby SM, and O'Leary TA (eds.) Adolescents, Alcohol, and Substance Abuse: Reaching Teens through Brief Interventions. Pp. 244274.

Chantala, K. \& Tabor, J. (1999). Strategies to Perform a Design-Based Analysis Using the Add Health Data. University of North Carolina at Chapel Hill.

Costello, D. M., Swendsen, J., Rose, J. S., \& Dierker, L. C. (2008). Risk and protective factors associated with trajectories of depressed mood from adolescence to early adulthood. Journal of Consulting and Clinical Psychology, 76, 173-183.

Curran PJ, Stice E, Chassin L. (1997). The relation between adolescent alcohol use and peer alcohol use: A longitudinal random coefficients model. Journal of Consulting and Clinical Psychology 65:130-140.

Donovan JE. (2004). Adolescent alcohol initiation: A review of Psychosocial Risk Factors. Journal of Adolescent Health35:529.e7-529.e18.

Duncan, T.E., Duncan, S. C., Stryker, L. A., Li, F., \& Alpert, A. (1999). An Introduction to Latent Variable Growth Curve Modeling: Concepts, Issues, and Applications. Mahwah, NJ: Erlbaum.

Ennett, S. T., \& Bauman, K. E. (1993). Peer group structure and adolescent cigarette smoking: A social network analysis. Journal of Health and Social Behavior, 34, 226-236.

Ennett, S. T. Bauman, K. E., Hussong, A., Faris, R., Foshee, V. A., \& Cai, L. (2006). The peer context of adolescent substance use: Findings from social network analysis. Journal of Research on Adolescence, 16, 159-186.

Fang, X., Li, X., Stanton, B., \& Dong, Q. (2003). Social network positions and smoking experimentation among Chinese adolescents. American Journal of Health Behavior, 27, 257-267.

Gil AG, Vega WA, Turner RJ. (2002). Early and mid-adolescence risk factors for later substance abuse by African Americans and European Americans. Public Health Reports 2002;117 Supplement 1: S15-S29.

Gomberg ESL. Alcohol abuse: Age and gender differences. (1997). In: Wilsnack RW and Wilsnack SC (eds.) Gender and Alcohol: Individual and Social Perspectives. Pp. 225-244. 
Harris, K. M., Halpern, C. T., Entzel, P., Tabor, J., Bearman, P. S., \& Udry, J. R. (2008). The National Longitudinal Study of Adolescent Health: Research Design [WWW document]. URL: http://www.cpc.unc.edu/projects/addhealth/design.

Hawkins, J. D., Catalano, R. F., \& Miller, J. Y. (1992). Risk and protective factors for alcohol and other drug problems in adolescence and early adulthood:

Implications for substance abuse prevention. Psychological Bulletin, 112, 64-105.

Henry, D. B. \& Kobus, K. (2007). Early adolescent social networks and substance use. Journal of Early Adolescence, 27, 346-362.

Johnston, LD, O'Malley, PM, Bachman, JG and Schulenberg JE. (2007). Monitoring the Future: National results on adolescent drug use: Overview of key findings, 2006.

(NIH Publication No. 07-6202). Bethesda, MS: National Institute on Drug Abuse.

Jones, B. L., Nagin, D. S., \& Roeder, K. (2001). A SAS procedure based on mixture models for estimating developmental trajectories. Sociological Methods and Research, 29, 374-393.

Keribin, C. (1998). Estimation consistante de l'ordre de modeles de mélange. Comptes Rendus de l'Academie des Sciences, Paris, Serie I: Mathematiques, 326, 243-248.

Kobus K. (2003). Peers and adolescent smoking. Addiction. 98 Supplement:37-55.

Laub, J. H., Nagin, D.S., \& Sampson, R. J. (1998). Trajectories of change in criminal offending: Good marriages and the desistance process. American Sociological Review, 63, 225-238.

Maney DW, Higham-Gardill DA, Mahoney BS. (2002). The alcohol-related psychosocial and behavioral risks of a nationally representative sample of adolescents. Journal of School Health 72:157-163

Mason WA, Windle M. (2001). Family, religious, school and peer influences on adolescent alcohol use: A longitudinal study. Journal of Studies on Alcohol 62:44-53.

McCarty CA, Ebel BE, Garrison MM, DiGiuseppe DL, Christakus DA, Rivara FP. (2004). Continuity of binge and harmful drinking from late adolescence to early adulthood. Pediatrics 114:714-719

Muthén, B. \& Shedden, K. (1999). Finite mixture modeling with mixture outcomes using EM algorithm. Biometrics, 55, 463-469.

Nagin, D. S. (1999). Analyzing developmental trajectories: A semiparametric groupbased approach. Psychological Methods, 4, 139-157.

Nagin, D. S. \& Tremblay, R. E. (2001). Analyzing developmental trajectories of distinct but related behaviors: a group-based method. Psychological Methods, 4, 139-177.

Nash SG, McQueen A, Bray JH. (2005). Pathways to adolescent alcohol use: Family environment, peer influence, and parental expectations. Journal of Adolescent Health 37: 19-28.

National Institute on Alcohol Abuse and Alcoholism. (2004/2005). Interventions for alcohol use and alcohol use disorders in youth. Alcohol Research \& Health 28:163-174

Nelson CB, Heath AC, Kessler RC. (1998). Temporal progression of alcohol dependence symptoms in US household population: Results from the National Comorbidity Survey. Journal of Consulting and Clinical Psychology 66:474-483.

Paschall M, Bersamin M, Flewelling RL. (2005). Racial/ethnic differences in the 
association between college attendance and heavy alcohol use: A national study. Journal of Studies on Alcohol 66:266-274.

Petraitis, J., Flay, B. R., \& Miller, T. Q. (1995). Reviewing theories of adolescent substance use: Organizing pieces of the puzzle. Psychological Bulletin, 117, 6786.

Pollard, M. S., Tucker, J.S., Green, H.D., Kennedy, D. \& Go, M-H. (2010). Friendship Networks and Trajectories of Adolescent Tobacco Use. Addictive Behaviors 35: 678-685.

Power TG, Stewart CD, Hughes SO, Arbona C. (2005). Predicting patterns of adolescent alcohol use: A longitudinal study. Journal of Studies on Alcohol 66:74-81.

Prendergast ML. (1994). Substance use and abuse among college students: A review of recent literature. Journal of American Coll. Health 43:99-113.

Prinstein MJ, Boergers J, Spirito A. (2001). Adolescents' and their friends' health-risk behavior: Factors that alter or add to peer influence. Journal of Pediatric Psychology 26:287-298.

Raudenbush, S. W. \& Bryk, A. S. (2002). Hierarchical Linear Models: Applications and Data Analysis Methods (Second Edition). Thousand Oaks, CA: Sage.

Richards, W. D. (1995). NEGOPY 4 30: Manual and User's Guide. Vancouver, Canada: Simon Fraser University.

Seary, A. J. (2005). Multinet: An Interactive Program for Analysing and Visualizing Complex Networks. Vancouver, Canada: Simon Fraser University.

Spear LP. (2000). Adolescent period: Biological basis of vulnerability to develop alcoholism and other ethanol-mediated behaviors. In: Noronha A, Eckardt M, Warren K (eds) Review of NIAAA's Neuroscience and Behavioral Research Portfolio. National Institute on Alcohol Abuse and Alcoholism Research Monograph No. 34, Bethesda MD: NIAAA.

Turner, K., West, P., Gordon, J., Young, R., \& Sweeting, H. (2006). Could the peer group explain school differences in pupil smoking rates? An exploratory study. Social Science and Medicine, 62, 2513-2525.

Turrisi R., Jaccard J. (1992). Cognitive and attitudinal factors in the analysis of alternatives to drunk driving. Journal of Studies on Alcohol 53:405-414.

Valente, T. W. (2003). Social network influences on adolescent substance use: An introduction. Connections, 25, 11-16.

Windle M. (2003). Alcohol use among adolescents and young adults. Alcohol Res. Health 27:79-85.

Windle M., Miller-Tutzauer C, Domenico D. (1992). Alcohol use, suicidal behavior, and risky activities among adolescents. Journal of Research on Adolescence 2:317-330. 
Table 1. Description of Study Variables

\begin{tabular}{|c|c|c|}
\hline Variable & Mean or Proportion & (SD) \\
\hline Male & 0.479 & 0.500 \\
\hline Age (at Wave 1) & 15.9 & 1.041 \\
\hline \multicolumn{3}{|l|}{ Race/ethnicity } \\
\hline Non-Hispanic White & 0.510 & 0.5 \\
\hline Non-Hispanic Black & 0.203 & 0.402 \\
\hline Hispanic & 0.177 & 0.382 \\
\hline Other & 0.110 & 0.276 \\
\hline Perceived Drinking Friends (Wave 1) & 1.193 & 1.174 \\
\hline \multicolumn{3}{|l|}{ Wave 1 Network Position } \\
\hline Member of Bingeing Group & 0.571 & 0.495 \\
\hline Member of Non-Bingeing Group & 0.084 & 0.224 \\
\hline Liaison to Bingeing Groups & 0.199 & 0.400 \\
\hline Liaison to Bingeing and non-Bingeing Groups & 0.068 & 0.253 \\
\hline Liaison to Non-Bingeing Groups Only & 0.031 & 0.105 \\
\hline Isolate & 0.047 & 0.192 \\
\hline Avg. Binges / month@Wave 1 & 1.012 & 3.650 \\
\hline Avg. Binges / month@Wave 2 & 1.210 & 4.000 \\
\hline Avg. Binges / month@Wave 3 & 1.750 & 4.421 \\
\hline
\end{tabular}

Note: $\mathrm{N}=1,648$ 
Table 2. Estimated Odds Ratios ${ }^{a}$ for Multinomial Logistic Regression Models Predicting Trajectory Membership

\begin{tabular}{lllll}
\hline & $\begin{array}{l}\text { Experimenter } \\
(\mathrm{n}=422)\end{array}$ & $\begin{array}{l}\text { Monthly } \\
\text { Binger } \\
(\mathrm{n}=619)\end{array}$ & $\begin{array}{l}\text { School } \\
\text { Binger } \\
(\mathrm{n}=73)\end{array}$ & $\begin{array}{l}\text { Young Adult Never-Binger } \\
\text { Binger } \\
(\mathrm{n}=63)\end{array}$ \\
\hline & & & & $\begin{array}{l}\text { (reference) } \\
(\mathrm{n}=471)\end{array}$ \\
& & & & \\
& $1.22 * * *$ & $2.35 * * *$ & $2.79 * * *$ & $2.14 * * *$ \\
Drinking best friends (at Wave 1) & & & & \\
& & & & \\
Member of a bingeing group & 1.09 & $2.87 * * *$ & $6.93 * * *$ & 2.23 \\
Liaison to bingeing groups only & 1.27 & $3.51 * * *$ & $8.53 * * *$ & $4.18 * *$ \\
Liaison to bingeing and non-bingeing & 1.11 & $2.07 * *$ & $3.59 *$ & 1.89 \\
Liaison to non-bingeing groups only & 0.61 & 1.13 & 1.67 & 0.79 \\
Isolate & 1.07 & 1.41 & 2.17 & 1.94 \\
Member of a non-bingeing group (reference) & & & & \\
\hline
\end{tabular}

${ }^{a}$ Models also control for gender, race/ethnicity, and age

${ }^{*} p<.05, * * p<.01, * * * p<.001$ 
Figure 1. Example Network Structure

Network Position

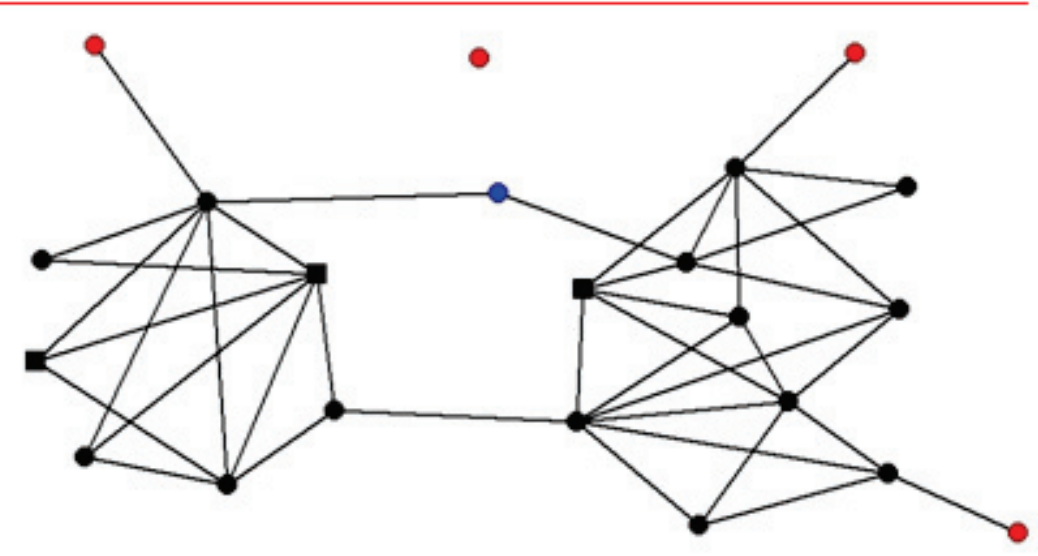

- Black $=$ Group Members $\quad$ - Circles = Non-Bingers

- Red = Isolates - Squares = Bingers

- Blue = Liaisons 
Figure 2. Average Binges Per Month, Grades 9-11 at Wave 1

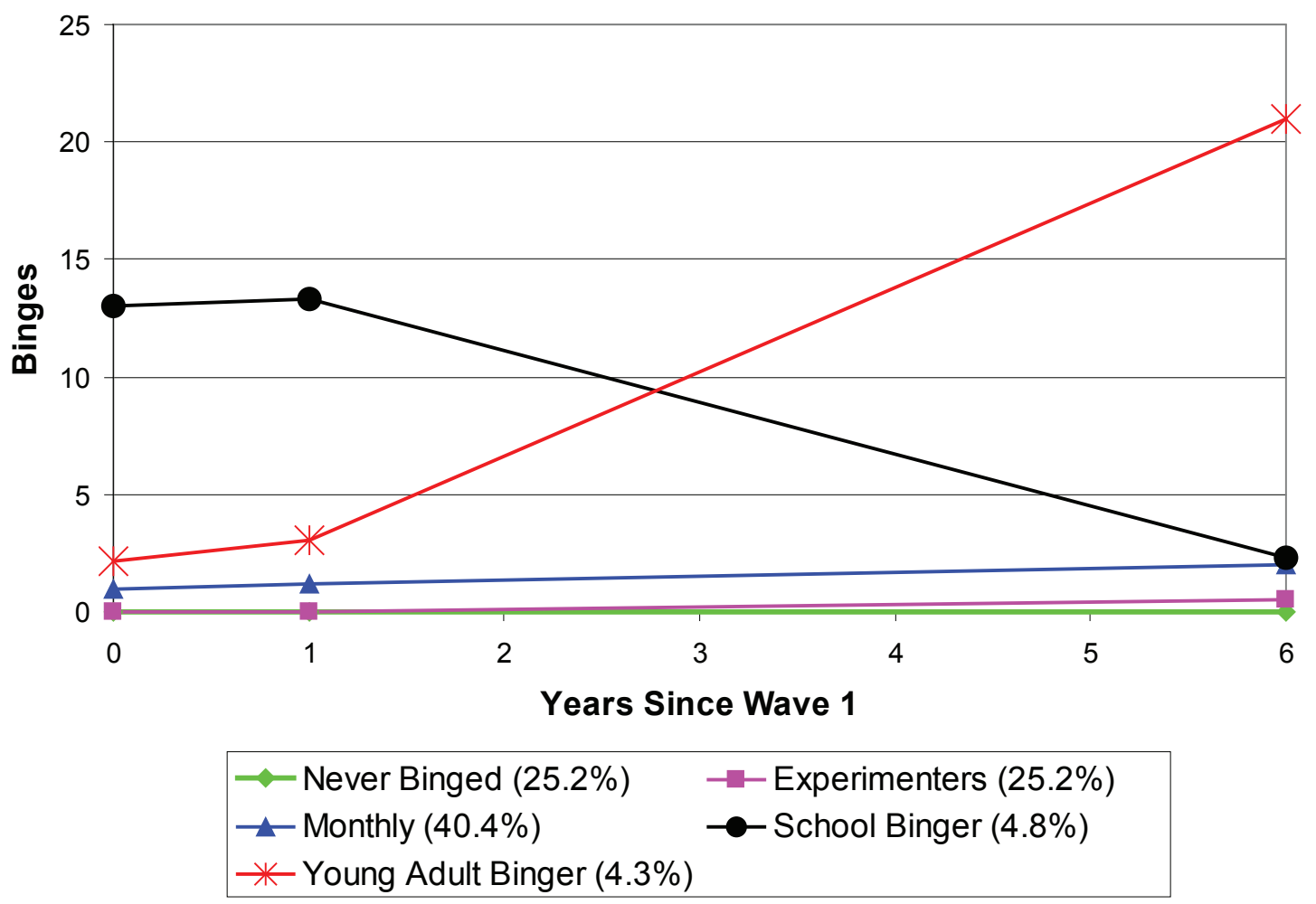

